\title{
RESOURCE-SAVING TECHNOLOGY BASED ON SEWAGE SLUDGE
}

\author{
Sanya Efremova $^{1, *}$, Ekaterina Polyanskova ${ }^{1}$, Aleksey Bodrov $^{1}$, and Ekaterina Parfenova ${ }^{1}$ \\ ${ }^{1}$ Penza State Technological University, 440039, Penza, Russian Federation
}

\begin{abstract}
The issues of waste disposal are currently having a global technological and economic complexity. The severity of the environmental problem is specified by the accumulation of large volumes of various wastes, including sewage sludge (SS). Modern technologies can provide its disposal with environmental and economic benefits. SS is a rich source of nutrients with a high fertilization potential. This work aims to study the utilization of wastewater sludge in recycling technology for agriculture. The composition of urban sewage sludge and its impact on the properties of gray forest soil were studied. It was shown that its application in a dose of 40-60 t/ha promoted an increase in the content of humus, mobile phosphorus and exchangeable potassium in the soil and a decrease in acidity. The noted increase in the content of the studied heavy metals upon the introduction of various doses of sludge did not exceed the approximate permissible concentration (APC) in the soil. The results showed that the use of SS as a fertilizer restores the balance of organic matter in soils and improves their agroecological properties. This technology, as a safe way of recycling waste into a valuable complex fertilizer, contributes to resource conservation.
\end{abstract}

\section{Introduction}

The problem of waste disposal has nowadays a global technological and economic complexity. Furthermore, the environmental protection from pollution and the development of resource-saving, waste-free technologies remain no less urgent [1].

The severity of the environmental problem is specified by the accumulation of large volumes of various wastes, including sewage sludge (SS) [2-4]. This creates unpredictability and can grow into an ecological catastrophe, as due to anthropogenic impact (constant pollution of ground and surface waters, soils, vegetation) every year it is aggravated and requires a solution.

Wastewater sludge is an unavoidable by-product of urban wastewater treatment plants. Now it is a key problem of many countries due to its increased volume and the consequences of disposal. Earlier sewage sludge was considered as waste due to the expected high levels of pollutants, which were often incinerated and disposed in landfills. At the present stage of technological development, the utilization of wastewater from urban wastewater treatment plants is highly relevant. According to Global Water Intelligence, in 2017 its world volume in dry matter is 83 million tons (an increase of $10.7 \%$ as compared to 2012) It is noted that about 2 million tons of sludge are produced in Russia per year [5].

In an era of depletion of natural resources, it is necessary to find ways to reuse and recycle waste. According to the hierarchy of waste management methods, disposal is the best alternative to landfills. As a part of the economic turnover, SS can be used in building technologies, road construction and the agricultural sector, and for the restoration of disturbed lands [6].

Wastewater sludge is known to be a rich source of nutrients with high fertilization potential [7,8]. In addition, it contains a large number of organic substances that can contribute to the bioavailability of macro-and micronutrients and improve soil structure [9]. But today in Russia technologies for the utilization of SS are not widespread. In foreign countries, about $40 \%$ of sludge is used in agricultural production (up to $83 \%$ in Spain, $68 \%$ in Great Britain, $41 \%$ in the USA); about $10 \%$ is used in Russia.

Due to the increasing number of SS and problems with its disposal, much attention is paid to this issue in modern scientific literature. A review of various aspects of sewage sludge utilization, presented in [7], shows that their introduction into soils can be economical, due to the contained nutrients and the actual removal of sewage sludge. Due to the high cost of mineral fertilizers, there is a tendency to increase the use of sewage sludge in agriculture, especially with intensive cultivation of crops in arid and semi-arid regions of Pakistan.

Sludge removal is not an easy task and an attractive option. In an experiment on calcareous soil [8], utilization was carried out through the soil-plant system. Sludge was used as a fertilizer, the possibility of simultaneously making a profit and minimizing metal pollution was shown.

\footnotetext{
* Corresponding author: $\underline{\text { s sharkova@mail.ru }}$
} 
Sludge has a profitable composition and content of organic matter in the dry mass (40-60\%), minerals (nitrogen - 1-3; phosphorus - 1-4; potassium - 0.2-0.7; calcium - 3-5\%, as well as other macro-and microelements), which can be transformed into accessible and safe forms for plants. So, it can be considered as an organic-mineral fertilizer [10-13].

Maintaining soil fertility is relevant in agriculture, and is associated with the reproduction of organic matter. This issue can be solved by the development and implementation of technologies using waste (manure, plant residues) [14] and the biologization of the production of mineral fertilizers $[15,16]$. Numerous studies prove that the use of SS as an organomineral fertilizer will restore the ecological functions of the soil and improve its properties [12, 17-19].

Studies [11] have shown that the use of sewage sludge as an organic fertilizer has advantages on acidic soils. It improves some chemical and physical properties: the amount of available forms of $\mathrm{K}, \mathrm{P}$, total $\mathrm{N}$, organic matter for plants has increased significantly, soil $\mathrm{pH}$ has decreased. So in general it is potentially a valuable fertilizer.

However, the use of sewage sludge can pose a risk due to the presence of components potentially damaging ecosystem which require careful characterization. The limited use of SS is associated with the possible accumulation of heavy metals (HM) in the soil and plants. To eliminate the danger of soil and cultivated products contamination with heavy metals, it is necessary to control their content [12,17,20-23].

According to American scientists, it is possible to use sludge as a fertilizer with a solid particle content not exceeding $30 \%$ and a HM concentration not exceeding the maximum permissible concentration (MPC) [10].

The purpose of this work was to study the utilization of SS in recycling technology on soil properties and its ecological functions.

\section{Materials and methods}

The studies were carried out on gray forest soils of the Penza region. The studied soil had a humus content of 2.09-2.12 \%. Mobile phosphorus content was 180.7$185.1 \mathrm{mg} / \mathrm{kg}$ of soil. Exchangeable potassium content was $114.8-118.1 \mathrm{mg} / \mathrm{kg}$ of soil in the arable layer.

SS was introduced for the main processing according to the following scheme: 1. Control (without fertilizers); 2. $40 \mathrm{t} / \mathrm{ha}$ of SS; $3.60 \mathrm{t} / \mathrm{ha}$ of SS. The experiment was repeated three times, the variants were placed by the method of randomized repetitions.

\section{Results and Discussion}

Chemical analysis of the experimental sludge of urban wastewater showed a weakly alkaline reaction: pHsal. was 7.87. Organic matter content (dry matter) was 67.2; phosphorus content was 1.12 ; potassium content was $0.37 \%$.

Analysis of the HM content showed results significantly below the permissible norm, they amounted to $(\mathrm{mg} / \mathrm{kg}): 12.99$ for $\mathrm{Pb}$; 0.39 for $\mathrm{Cd} ; 40.34$ for $\mathrm{Cu}$; 78.41 for $\mathrm{Zn}$; 4.73 for $\mathrm{Cr}$. The moisture content of the sludge in all studied samples was $61-67 \%$, which in general corresponds to the regulatory requirements for sludge used as fertilizer in accordance with the Russian Sanitary regulations and standards SaNPiN 2.1.7.573 96.

The studied influence of SS on the properties of gray forest soil showed a shift in the medium reaction to alkali (Fig. 1).

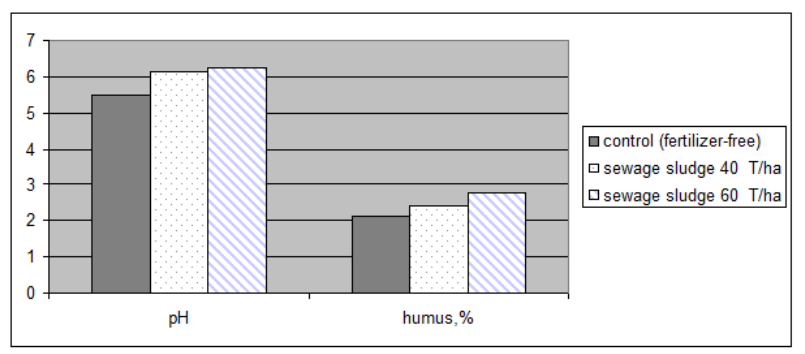

Fig. 1. The influence of SS on soil acidity and fertility.

A decrease in the exchangeable acidity of the studied soils was reliably obtained with a single application of various doses. An increase in the humus content was observed, which is quite explainable by the high content of organic matter in the sludge.

The relationship between the acidity decrease and the applied dose is characterized by the approximation reliability value $\mathrm{R}^{2}=0.998$; and for humus this value is $\mathrm{R}^{2}=0.849$.

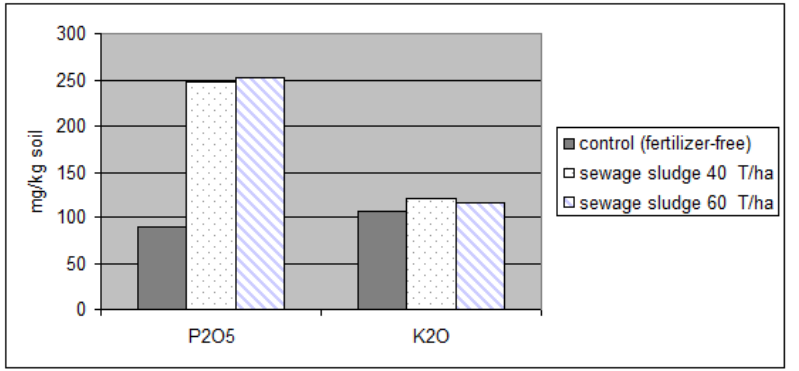

Fig. 2. The influence of SS on soil mineralization.

Figure 2 shows the change in the content of minerals, in particular the increase in mobile phosphorus and exchangeable potassium in comparison with the control sample. The data obtained indicate a significant improvement in the agrochemical parameters of the gray forest soil.

From an ecological point of view, the most important indicator is the content of HMs in soil after the introduction of sewage sludge. Their content in SS depends on the concentration in the effluent entering the treatment plant. 


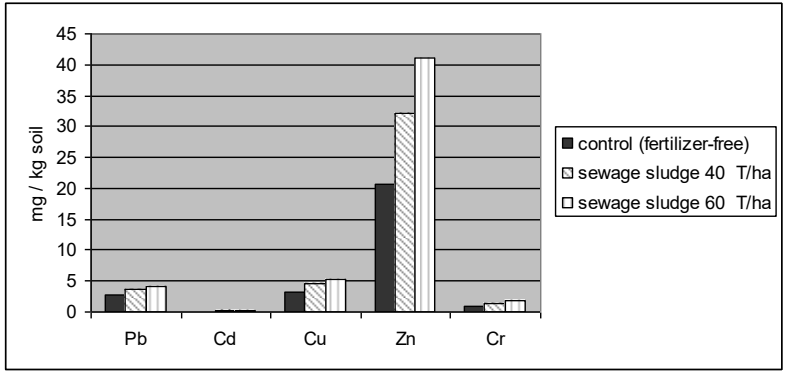

Fig. 3. The content of heavy metals in the soil as a function of $\mathrm{SS}$ introduction.

Figure 3 shows the increase in the content of all metals with the introduction of various doses of sludge. However, the analysis of the obtained results of the studied samples did not reveal an excess in the gross HM content in the soil considering the approximate permissible concentration in the soil 130 for $\mathrm{Pb}, 2$ for $\mathrm{Cd}, 132$ for $\mathrm{Cu}, 220$ for $\mathrm{Zn}, 6$ for $\mathrm{Cr}$ (mg/kg).

\section{Conclusion}

The study considers the feasibility of resource-saving technologies based on sewage sludge. The conducted experiment showed that the use of urban sewage sludge at doses of 40 and $60 \mathrm{t} / \mathrm{ha}$ will restore ecological functions and improve soil properties. A decrease in acidity by $0.6-07$ units, increase in organic matter by $0.23-0.64 \%$ were detected. This ensures obtaining environmentally friendly products and can be recommended to use on gray forest soils. The results showed that its utilization as an organic fertilizer would give the best results. Firstly, it would help to restore the balance of organic matter in soils and improve their agrochemical properties. Secondly, sludge is a valuable complex fertilizer with a high content of basic nutrients and microelements and is a safe way to utilize these wastes. The data obtained are consistent with experimental data from other European and Asian countries, which showed variability in all types of the considered soils.

For the safe use of SS, some recommendations can be drawn based on the identified relationships. The sludge should be used with mandatory control of the chemical composition. Its utilization to improve the agrochemical properties of gray forest soil is rational in doses of $40-60 \mathrm{t} / \mathrm{ha}$.

\section{References}

1. E.G. Kulikova, S.Yu. Efremova, Assessment of energy-saving farming technology in ensuring environmental safety, XXI century: results of the past and problems of the present plus, no. 5-6 (3940), pp. 67-76 (2017)

2. N.A. Sobgaida, L.N. Olshanskaya, A.B. Solodkova, Ecological problems of utilization of waste activated sludge of saratov refinery and ways to solve them, Chemical and Petroleum Engineering, 47(3), P. 198203 (2011)
3. S.Y. Efremova, N.I. Akanova, T.A. Sharkov, M.I. Yakhkind, Efficiency of the use of neutralized phosphogypsum, phosphorite processing waste, in agriculture, Environmental Quality Management, 30 (2), 5-11 (2020).

4. M.Yu. Loktionov, I.A. Shilnikov, A.Kh. Sheudzhen, N.I. Akanova, S.Yu. Efremova. Ecological and agrochemical efficiency of the use of neutralized phosphogypsum in agriculture, XXI century: the results of the past and the problems of the present plus, no. 5 (27), pp. 134-146 (2015)

5. Neutralization of sewage sludge [Electronic
[E resource]URL: http://www.greenpik.ru/sections/96.html \&article $=17$

6. Drozd G.Ya., Proposals for the involvement of deposited sewage sludge into economic turnover, Materials of the International Congress "ETEVK2009", Yalta, pp. 230-242 (2009)

7. K Usman, S Khan, S Ghulam, MU Khan, N Khan, Sewage Sludge: An Important Biological Resource for Sustainable Agriculture and Its Environmental Implications, American Journal of Plant Sciences, 03, 1708-1721 (2012)

8. H.K. Ahmed, H.A. Fawy, E.S. Abdel-Hady, Study of sewage sludge use in agriculture and its effect on plant and soil, in Agriculture and Biology Journal of North America 1:1044-9 (2010).

9. H. Kominko, K. Gorazda, Z. Wzorek, The possibility of organo-mineral fertilizer production from sewage sludge, Journal of Waste \& Biomass Valorization 8:1781-1791(2017)

10. M. Jamil, M. Qasim and M. Umar, Utilization of Sewage Sludge on Organic Fertilizer in Sustainable Agriculture, Journal of Applied Science, Vol. 6, No. 3, 531-535 (2006).

11. S. Vaseghi, M. Afyuni, H. Shariatmadari, M. Mobli, Effect of sewage sludge on some nutrients concentration and soil chemical properties, Journal of Isfahan Water and Wastewater, 53: 15-19 (in Persian) (2005).

12. M.J. Mohammad, B.M. Athamneh, Changes in soil fertility and plant uptake of nutrients and heavy metals in response to sewage sludge application to calcareous soils, Journal of Agronomy https://www.researchgate.net/journal/Journal-ofAgronomy-1812-54173, 229-236 (2004).

13. J.S. Mtshali, A.T. Tirunech, A.O. Fadiran, Characterization of sewage sludge generated from waste water treatment plants in Swaziland in relation to agricultural uses, in Journal of Resources and Environment. 4 (4),190-199 (2014).

14. E.G. Kulikova, S.Yu. Efremova, Utilization of woodworking waste in agriculture, XXI century: the results of the past and the problems of the present plus, No. 1 (17), pp. 103-109 (2014)

15. Y. Koryagin, E. Kulikova, S. Efremova, N. Sukhova, The influence of microbiological fertilisers on the productivity and quality of winter 
wheat, Plant soil and environment, 66 (11), 564-568 (2020)

16. S.Y. Efremova, I.V. Kulikova, N.V. Sukhova, Agroecological efficiency of biomodified mineral fertilizers, E3S Web of Conferences. International Conference on Efficient Production and Processing, ICEPP (2020).

17. T.A. Nogueira, A. Franco, Z He, V.S. Braga, L.P. Firme, C.H. Abreu Jr. Short-term usage of sewage sludge as organic fertilizer to sugarcane in a tropical soil bears little threat of heavy metal contamination, Journal of Environmental Management 114:168177 (2013)

18. E.M. Eid, S.A. Alrumman, A.F. El-Bebany, K.F. Fawy, M.A. Taher, A. Hesham, G.A. El-Shaboury, M.T. Ahmed, Evaluation of the potential of sewage sludge as a valuable fertilizer for wheat (Triticum aestivum L.) crops., Journal of Environmental Science and Pollution Research 26:392-401 (2019).

19. N. Roig, J. Sierra, E. Marti, M. Nadel, Schuhmacher and J.L. Doming, Long-term amendment of Spanish soils with sewage sludge: Effects on soil functioning, Journal Agriculture, Ecosystems \& Environment 158: 41-48. (2012).

20. T.H. Chatha, R. Hayat, I Latif, Influence of sewage sludge and organic manures application on wheat yield and heavy metal availability, Asian Journal of Plant Sciences, 1: 79-81 (2002).

21. L. Lamastra, N.A. Suciu, M. Trevisan, Sewage sludge for sustainable agriculture: contaminants' contents and potential use as fertilizer, Journal Chemical and Biological Technologies in Agriculture 5, 10 (2018).

22. L.V. Mosina, E.A. Dovletyarova, S.Yu. Efremova, J. Norvosuren, Ecological hazard of soil pollution by heavy metals (on the example of lead), Izvestia of the Penza State Pedagogical University named after V.G. Belinsky, No. 29, pp. 383-386 (2012).

23. S. Efremova, E. Parfenova, A. Bodrov, Environmental hazard of soil contamination by heavy metals, Paper presented at the E3S Web of Conferences, Industrial Future of Territories, IFT 208, 01021 (2020). 